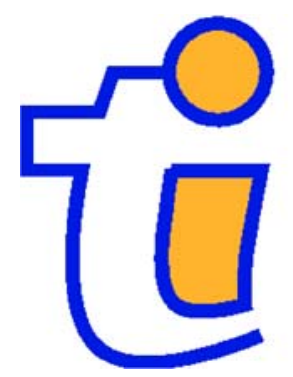

TI 2003-039/3

Tinbergen Institute Discussion Paper

Turbulence, Flexibility and Performance of the Long-lived Small Firm

\author{
Bernadette Power \\ Gavin C. Reid*
}

+ University College Cork, Cork, Ireland,

* Department of Economics, University of St. Andrews, St. Andrews, Scotland, UK, and Tinbergen Institute. 


\section{Tinbergen Institute}

The Tinbergen Institute is the institute for economic research of the Erasmus Universiteit Rotterdam, Universiteit van Amsterdam, and Vrije Universiteit Amsterdam.

Tinbergen Institute Amsterdam

Roetersstraat 31

1018 WB Amsterdam

The Netherlands

Tel.: $\quad+31(0) 205513500$

Fax: $\quad+31(0) 205513555$

Tinbergen Institute Rotterdam

Burg. Oudlaan 50

3062 PA Rotterdam

The Netherlands

Tel.: $\quad+31(0) 104088900$

Fax: $\quad+31(0) 104089031$

Please send questions and/or remarks of nonscientific nature to driessen@tinbergen.nl.

Most TI discussion papers can be downloaded at http://www.tinbergen.nl. 


\title{
Turbulence, Flexibility and Performance of the Long-lived Small Firm
}

\author{
Bernadette Power ${ }^{+}$and Gavin C Reid*
}

\begin{abstract}
This paper focuses on a new concern in the small firm's literature, namely what makes a small firm stay in business for a long time. It reflects a change in economic policy, away from an emphasis on volume of start-ups to an emphasis on quality of start-ups. The basic hypothesis is that flexibility enhances the long run prospects of the small firm. This is explored by examining precipitating causes of organisational change within the small firm, and the consequential adjustments. The study is fieldwork based and uses evidence from face-to-face interviews with 63 owner managers of mature small firms in Scotland. New measures of flexibility and turbulence are used to explain the performance of mature small firms. These depend on our unique body of evidence from interviews with owner managers. Performance is measured using a Likert scale over 28 distinct attributes.

Econometric estimates are reported on the relationship between flexibility, turbulence and performance. This is done in two forms. The first involves generalised least squares estimation (with heteroskedastic adjustment) of the relationship between turbulence, four measures of flexibility, and performance. The second involves Heckman sample selection estimation, of this performance relationship. It is found that turbulence has a negative effect on performance. Further, this impact is relatively large. Next in importance are those flexibility factors which can be categorised as precipitating causes of organisational change (as opposed to consequential adjustments) within the mature small firm. Finally, trade-off relationships are found to exist between two of the measures of flexibility (viz. agility and speed). We believe that this trade-off relationship is worthy of further empirical investigation.
\end{abstract}

\section{Keywords: Flexibility, Turbulence, Performance, Small Firms}

\section{JEL: $\quad$ C42, D21, G33, L2, M13, M21}

* Author for Correspondence: Professor in Economics, and Director, Center for Research into Industry, Enterprise Finance and the Firm (CRIEFF), Department of Economics, University of St. Andrews, St. Salvator's College, St. Andrews, Fife, Scotland, KY16 9AL, UK.

e-mail: $\quad$ gcr@st-andrews.ac.uk

Phone/Fax: (+44) (0) 1334462431 (personal); (+44) (0) 1334462438 (CRIEFF)

www: $\quad$ http://www.st-and.ac.uk/ $\sim$ www crieff/CRIEFF.html

${ }^{+}$Lecture in Economics, Dept. of Economics, University College Cork, Cork, Ireland

e-mail: b.power@ucc.ie

Phone: (+353) (0) 214902986

Fax: $\quad(+353)(0) 214273920$

www: http://www.ucc.ie/ucc/depts/economics/staff/power.html 


\section{Summary}

The paper explains the performance of long-lived small firms in terms of turbulence and flexibility. It introduces new measures of performance and flexibility. The latter reflect the agility and speed of long-lived small firms in responding to change. The evidence suggests that a trade-off exist between some dimensions of agility, and speed in responding to changes. Such trade-offs arise from the complex relationship between flexibility and performance. Thus the owner-manager of the small firm has to assess the implications for performance of committing resources to a particular strategic change today, as opposed to tomorrow. Our measure of firm specific turbulence had a negative effect on performance. This suggests that many long-lived small firms correct for past inflexibilities and poor performance in order to survive. Turbulence had a larger impact on performance than did firm flexibility, in adjusting to change. We found that the impact of precipitators of change was considerable, and partly counteracted the negative influence of turbulence on firm performance.

\section{Introduction}

In this paper we explore the relationship between turbulence, flexibility and performance. We do so using data collected in face-to-face interviews with 63 long-lived small firms in Scotland. We define long-lived small firms as businesses that have been trading for more than 10 years. They were classified as small firms at inception if they employed less than 100 people. In fact, the small firms in the study were much smaller, typically having 10 employees at inception. Today, our long-lived small firms had 13 employees, on average, indicating some, but not substantial growth since inception.

We reserve until Section 4 our account of the details of how we measured turbulence, flexibility and performance. Here we will put the matter more briefly. The agility of long-lived small firms was calibrated by the ratio of precipitators of organisational change to their consequential adjustments. Speed was measured by the time it took a firm to adjust to precipitators of organisational change. Turbulence was measured by a count of the number of changes undertaken over the lifetime of the longlived small firm. Performance was measured using a self-appraised multidimensional 
scale. This incorporated aspects of: competitive environment; financial management; organisational structure; and business strategy. Such a measure is adopted because the flexibility of a firm is not always captured by increases in financial measures of performance. Organisational changes may be undertaken solely to maintain performance or in other words for sheer survival. A broader measure of performance is thus required to capture the relationship between flexibility and performance.

The flexibility of small firms explains their growth and viability, see Evans and Brock (1989), Piore and Sabel (1984) and Acs, Audretsch and Carlsson (1990). Thus small firms survive and prosper, alongside larger firms, because of their relative flexibility. For example, smaller firms are more flexible because they have proportionately fewer impediments to organisational change. To illustrate, they have lesser need to employ hierarchy to control their operation, Reid (1997). Another argument would be that small firms are relatively more flexible because they offer opportunities for the greater intensity of utilisation of variable factors of production. An illustration of this would be their tendency to the casualisation of labour to enhance performance, Reid (1999).

We would agree with Carlsson (1989) that the development of theoretical ideas about flexibility has been to the detriment of improving our knowledge about of its empirical dimensions. Carlsson (1989) identified three important aspects of flexibility in his empirical examination of larger firms. These were operational, tactical and strategic flexibility. Our approach differs from Carlsson in two respects: first we focus on small firm, rather than large firms; and second we focus on the aspect that he found most difficult to calibrate, strategic flexibility.

Earlier evidence on the relationship between flexibility and performance was provided by Smallbone, North \& Leigh (1992). They found that firms which had been active in making adjustments were the most successful, in terms of employment change and survival. They used data from mature manufacturing firms in the UK. However, they did not examine the process, or speed, by which adjustments were made, nor did they look at performance implications of such adjustments. Our work aims to remedy these shortcomings of earlier work.

Briefly the development of our ideas is as follows. Section 3 examines the measurement of performance, flexibility and turbulence in the literature. Section 4 
discusses the primary source data on which this study is based. Section 5 reports the results of a Heckman selection model, which estimates the effects which flexibility and turbulence have on performance. Finally, Section 6 summarises our principal results.

\section{Flexibility, Turbulence and Performance}

This section aims to achieve three things. First, it discusses concepts of flexibility and turbulence. Further, we describe how turbulence, agility and speed are to be measured. Second, we discuss conceptual problems of the measurement of performance, leaving to Section 4 the explicit consideration of how we calibrate performance. Third, we discuss briefly the effects we expect flexibility and turbulence to have on performance.

\subsection{Measuring Flexibility and Turbulence}

According to Stigler (1939) a firm's choice of cost structure determines its level of flexibility. The shape of the cost curve determines how responsive output decisions are to price changes. Flexibility is greater with flat-bottomed average cost curves, and flat or gently inclined marginal cost curves, in the context of U-shaped cost curves. Central to Stigler's notion of flexibility is the idea that expected profit will increase with greater flexibility. Thus, the more flexible a firm is, the higher its expected performance. The marginal gain is greater, the greater is environmental uncertainty. Thus greater flexibility is preferred to lesser flexibility, when the environment is uncertain.

Mills and Schumann (1985) associated the notion of greater flexibility with smaller, rather than larger firms. They argued that small firms achieved greater flexibility through their ability to alter variable factors of production more readily. ${ }^{1}$ This source of flexibility enables small firms to thrive in uncertain environments. Mills and Schumann (1985) relied on Stigler's (1939) view that flexibility should be inversely related to the convexity of the cost function. This can be measured by the elasticity of supply at the mean price, where it is assumed that price equates supply and demand, when the environment is uncertain. Empirically, the Mills and Schumman (1985) measure of flexibility was approximated by an index of firm sales variability or employment variability. ${ }^{2}$ Other measures adopted were those of Acs, Audretsch and Carlsson (1990). They explained increases in small firm presence, and decreases in mean plant size, using 
measures of change in production technology. Measures of flexible production technologies explain both the growth in small firms and decreases in the mean plant size. Examples of these measures include: the percentage share of the total number of machines accounted for by numerically controlled machines; the percentage share of the total number of machines accounted for by programmable robots; and the capital labour ratio. These measures of flexibility were found to be suitable approximations, given the availability of data.

In examining flexibility in the theory of the firm, Carlsson (1989) argued that flexibility is not necessarily inherent in small firms. Rather, it arises from the ability of small firms to use variable factors of production as their source of flexibility. This occurs because the existence of few organisational barriers allows small firms to mount a quick response to detected changes in their environment. Relevant to this perspective is Ghemawat's (1991) view on the source of flexibility. He would hold that flexibility arises from the expected added value which the firm can generate from revising its strategy. It does so by adopting alternative courses of action, as the outcomes of uncertain events unfold.

Although Ghemawat (1991) developed the idea in a corporate context, it is also entirely applicable to the small firms' case. Thus it is as true for small firms as for large firms that the value added created by flexibility arises in some sense from "the degree of preparedness". Specifically this refers to the ability of the firm to commit the necessary resources to pursuing different courses of action. Flexibility in this sense is not the optimisation of strategy, but rather the selection of strategies that can be adapted to a range of critical outcomes.

Ghemawat's (1991) conception of flexibility, adapted in our case to the small firm's context, has been influential in our formulation of dimensions of flexibility. In this paper we refer to them as agility and speed. Agility arises from the ability of the small firm to use variable factors of production to assist in achieving adaptations to its internal organisational structure. Thus the agile small firm is responsive to change or prepared for change. Speed is measured by the ability of the small firm to act expeditiously in the face of both precipitating influences (arising from its environment), and consequential adjustments (arising from its own organisational change). Thus the speedy small firm acts 
quickly before and after internal organizational change. The lower the reaction-time to detect changes in the environment, the more flexible the firm is.

As well as acting on precipitating influences and consequential adjustments, the small firm needs to be able to detect that circumstances have changed per se. To illustrate, Mata (1993) has found that detecting precipitating influences can be a source of flexibility in small firms, and this ability differs across owner mangers. He found that if owner managers within the small firms' sector were not alert to detecting environmental changes, the presence of small firms would not grow.

There is some deviation in our treatment of turbulence from that used in other parts of the literature of industrial organization. A common approach is that Beesley and Hamilton (1984) who approximated turbulence by accounting for flows in the birth and death of firms in particular industries. However their measure is industry specific rather than firm specific. Closer to our approach is the case study evidence of Markusen and Teitz (1985). In their work, which concerned the underlying dynamics of the competitive environment in which mature small firms operated, they found that the markets of such firms were turbulent. Thus, all firms in the sample were expecting some change, whether in the form of a crisis or of a growth opportunity. Our approach, following Markusen and Teitz (1985), as opposed to Beesley and Hamilton (1984), is to measure turbulence at the firm level. In this paper, turbulence is estimated by a count of the number of changes undertaken by the mature small firm, qua organisation, over its lifetime. Thus a relatively high number of changes signals that the mature small firm is operating in a turbulent environment.

\subsection{Measuring Performance}

Several approaches to measuring performance in small firms are possible. For example Reid and Smith (2000) identify three. In particular, they contrast an objective measure (e.g. quantitative measures like profitability and rate of return) with a subjective measure (e.g. a judgmental evaluation of performance, drawing on both quantitative and qualitative evidence). In this paper we adopt the latter approach. It is both more comprehensive, and more compatible with our evidence base. The requirement for a comprehensive measure of performance is consistent with the literature on 
entrepreneurship and management accounting as applied to the small firm e.g. Wickham, (2001, Ch. 20). Essentially it recognises that the proper control of the firm requires a comparison of current performance to a predetermined plan or objective. This approach would see there being an indissoluble link between the setting of performance standards and the control of the firm by the owner manager. The most commonly conceived performance standards relate to budgets. However there are many other forms including those relating to human factors, like responsibility, and technological ones, like hitting research milestones. As regards the compatibility of the evidence base, the subjective measure of performance evaluation allows us to undertake modelling which is currently not possible given our sample (see Endnote 3). Our sample is actually composed of three sub-samples. Each sub-sample typically has a different range of objective performance measures gathered at different points in time. There is therefore an intrinsic lack of comparability of these measures over the lifetimes of the firms. Resorting to a new performance measurement approach, which is common to the three sub-samples, allows us to proceed with empirical work on a common basis.

The firms examined in this study have, in a sense, passed the long run test of economic survival, and satisfied the aspirations of their founders. Thus owner-managers have before them a body of qualitative and quantitative evidence from which they can evaluate their performance. Naturally there are many dimensions to this performance. To illustrate, over time they have learned how best to combine their factors of production to exploit market opportunities, and they have responded to threats in a way that has improved their performance and enhanced their survival. Given that owner mangers comfortably juggle these various performance measures in their own minds, we consider it logical to explicitly measure the subjective processes by which this juggling act is sustained. To the extent that this measuring exercise is successful, it provides us with a new form of empirical evidence which is useful in econometric estimation.

\subsection{Performance, Flexibility and Turbulence}

This subsection examines the expected causal relationship between flexibility and turbulence (as independent variables) and performance (as dependent variable). In general greater flexibility is expected to have a positive effect on performance. This is 
true of approaches to flexibility as diverse as those of Stigler (1939) and Ghemawat (1991). Firm flexibility has been shown to explain relatively greater small firm presence in uncertain environments. This increased presence is therefore indicative of enhanced small firm performance.

As compared to the unambiguous effect of flexibility, the effect of turbulence on performance is less clear. In general, a higher number of organisational changes would reflect a greater degree of turbulence and visa versa however it does not automatically imply improved performance. Reid and Smith (2000b) found that both poorly performing ("stagnant") firms and high performing ("adaptive") firms have relatively active discretionary policies. Whereas stagnant firms frequently adopt organisational changes to counteract the consequences of inflexibility in terms of poor performance, adaptive firms frequently adopt organisational changes to facilitate greater growth and other aspects of improved performance.

In general the greater the number of consequential adjustments relative to the number of precipitating causes the less agile is the firm. Here we are interpreting agility as one aspect of performance. The greater the agility of the small firm the better its performance should be. If speed is measured by the time taken to respond to both precipitating influences and consequential adjustments, we should expect speed (in this sense) to influence performance negatively. As we shall see below, when we come to the econometric estimates, it may also be necessary to consider potential tradeoff relationships between agility and speed.

\section{Data and Variables}

This section presents information on the database and the variables used in econometric estimation. It also provides some amplification of the key hypotheses being addressed, and of the instrument design especially, as it relates to the measuring of performance.

\subsection{Database}

Briefly the data set that we used for econometric estimation was based on interview evidence obtained from owner managers of long-lived small firms in Scotland. Our 
sampling frame of 90 long-lived small firms was derived from three "parent" samples of Scottish small business enterprises ${ }^{3}$. These parent samples related to previous fieldwork studies undertaken in the 1980s and 1990s by one of the authors. The parent samples, from which these long-lived small firms were identified, may safely be viewed as random samples from the population of small firms in Scotland at the time of the initial interviews. ${ }^{4}$ They provided a convenient set of known sources upon which further fieldwork could be built. Considerable benefit derived from previous contact with entrepreneurs in terms of access to the field. Generally owner managers were happy to be looked up again after long lapses of time.

This approach to identifying long-lived small firms was found to be superior to that offered by the use of independent sources, such as Dun and Bradstreet. There are two reasons for this. (1) Proceeding in our way, data are available on non-survivors, which would not be the case with Dun and Bradstreet. This allows us to analyse the consequences of different strategies adopted by survivors, compared to non-survivors. (2) Importantly, it allows us to correct for sample selection bias in estimating a performance equation.

Of the 90 owner mangers of firms contained in our sampling frame, 63 were willing to be interviewed face to face between October 2001 and February 2002 (a 70\% response rate). The owner managers were interviewed using an administered questionnaire. This examined the characteristics of the long-lived small firm, changes in its scale and scope, an analysis of pivotal changes in the running of the firm since startup, factors which fostered the survival of the firm and the level of innovation and technical change within the firm. General features of the database and the variables used in the course of this analysis are described immediately below.

The firms examined were mature ( $251 / 2$ years on average; median age of 22). Almost all sectors by SIC were represented in the sample from agriculture (01) to domestic services (99). The main sectors represented were: 32, mechanical engineering $(4.8 \%) ; 43$, textile industry $(4.8 \%) ; 61$, wholesale distribution $(4.8 \%) ; 64$, retail distribution (23\%); 66, hotels and catering (4.8\%), 67 repair of consumer goods and vehicles (6.3\%); and 83 business services $(9.5 \%)$. The modal firm was a retailer. The sample proportions between extractive/manufacturers (SIC 01-60) and services (SIC 61- 
99 ) were $37 \%$ and $63 \%$ respectively. These proportions were similar across each of the 'parent' samples. Of the 267 firms in the three parent samples $101(38 \%)$ were in manufacturing (SIC 01-60) and 166 (62\%) were in services (SIC 61-99). Figures from the Department of Trade and Industry, for the UK as a whole, suggest that $27 \%$ were in manufacturing and $73 \%$ were in services. Thus there is a slight bias towards manufacturing firms in our sample. This partly explained by the slower progression of the Scottish economy to becoming service based, compared to the UK as a whole. It is also probably partly explained by the fact that the parent samples were drawn from the caseloads of Enterprise Trusts. These are business incubation units within Scotland, which in the early years may have had a tendency to favour manufacturing start-ups. The geographic scope of the sample was extensive. The following regions were represented: Aberdeen, Argyll, Aryshire, Banff, Caithneas, Cumnock, Dundee, Fife, Glasgow, Inverness, Isle of Skye, Lanarkshire, Lothian and Edinburgh, Midlothian, Moray, Orkney, Perth, Renfrewshire, Ross and Stirling.

Of the sample of 63 long-lived small firms, one (1.6\%) was a sole trader operating from home, fifteen $(23.8 \%)$ were sole traders operating from business premises, nineteen (30.2\%) were partnerships and twenty-five (44.4\%) were private limited companies. Eighteen $(28.6 \%)$ firms changed their legal form during the life of the business. There is general evidence of changes in organisational form, from the sole proprietorship form, to the partnership and private limited company forms, over the lifetimes of the firms, $c f$. Reid (1997). The number of full-time equivalent (FTEs) employees, which is one indicator of the size of these small business enterprises, varied from 1 to 130 with the average and mode being 13.55 and 6 respectively. The average size of firms (and the corresponding standard deviation) in terms of full time equivalent employees were as follows: 5.94 (5.85), sole proprietorship; 7.91(4.08), partnership; and 22.19 (27.69), private company. Size, measured by turnover for the last trading year, also varied widely by business type. Average turnover (and its standard deviation) was: $£ 219,813$ (£143,025) for sole proprietorships; £557,526 (£455,994) for partnerships; and $£ 1,372,821$ ( $£ 1,885,391)$ for private companies (all figures in 2001 prices). 


\subsection{Variables}

This subsection is concerned with summary statistics on the key variables used, detailed explanation of how they are defined, and an explanation of how the questionnaire design was used to generate variables. In Table I we indicate the key variables that we used in the econometric modeling reported on in Section 5 below.

Age and employees are fairly self-explanatory. Concerning age, it is very evident that we do indeed have a sample of long-lived firms. The average age is about 26 years, (roughly one generation) and no firm was younger than 10 years old. The maximum age in the sample was 90 years (roughly two generations). It should be mentioned that generational issues are of central importance, because many of these mature small firms are family businesses. After one generation, owner managers are frequently looking for exit strategies. A fairly obvious choice is family succession. Given generally favourable conditions in the labour market, and an increasing variety of job options, it turns out that family succession is by no means a foregone conclusion. For this reason the generational effect may have some impact on the lifecycle behaviour of the mature small firm. This is not something that we have explicitly examined but feel that it is worthy of examination in future work.

In terms of firm size (measured by full-time equivalent employees) these mature small firms are on average just above the size of the micro firm (10 employees or less). However the predominant firm type is still the micro-firm and the average size is somewhat raised by the existence of a few large firms in the sample. Essentially, the size distribution of these small firms is something like a Pareto distribution (that is one branch of an hyperbola in the first quadrant), with unity as the lower bound. The variables turbulence, agility and speed have already been discussed in a preliminary way, and are essentially components of our econometric modeling (see Section 5 below). The remaining variables in Table 1, and their construction, will be discussed in the remainder of this sub-section. 
Table 1

Mean, standard deviation and range of each variable

\begin{tabular}{|l|r|r|r|r|}
\hline Variable & \multicolumn{1}{|c|}{ Mean } & \multicolumn{1}{|c|}{$\begin{array}{l}\text { Standard } \\
\text { deviation }\end{array}$} & Min \\
\hline Age & 25.54 & 15.73 & 10 & 90 \\
\hline Employees (FTEs) & 13.55 & 19.89 & 1 & 130 \\
\hline Turbulence & 7.90 & 3.8 & 2 & 16 \\
\hline Agility & .8737 & .4070 & .22 & 2.38 \\
\hline Speed & 21.84 & 16.19 & 2.45 & 73.9 \\
\hline Precipitator & 5.27 & 2.72 & 1 & 15.67 \\
\hline Adjust & 7.31 & 3.33 & 1.67 & 16 \\
\hline PrecipitatorTime & 75.60 & 62.28 & 0 & 260 \\
\hline AdjustTime & 54.35 & 75.18 & 0 & 476.33 \\
\hline Perform & 67.35 & 8.10 & 49.11 & 90.43 \\
\hline
\end{tabular}

Turbulence was calculated using a frequency count of the number of key organisational changes to which long-lived firms were subject, over their lifetimes. Owner-managers were presented with a list of eighteen such changes. This list was diverse, including features like ownership, legal form, technical, location, cashflow, line of business, capacity, investment, product range, market positioning, diversification and management. The occurrence of key organisational changes (and the year in which they occurred) was recorded. ${ }^{5}$ Owner managers were not limited to those listed. They were allowed to specify other main changes if they wished.

These key changes can be can be interpreted as critical decisions. Throughout the course of its life the mature small firm makes such decisions. Crucially, these critical decisions involve the commitment of resources (Ghemawat, 1991). Such changes can have positive or negative impact. When we refer to the performance variable, the implications of this will be drawn out. Essentially, our key changes are to be interpreted as 'pivotal points' or 'crossroads', rather than as crisis points. Typically they are strategic in nature, and at one remove from the more routinised decisions undertaken by the mature small firm on a day-to-day basis. Because of this, the consequences of these key changes are typically unpredictable: there is always a measure of uncertainty about the outcomes of such changes. They are treated below as contingent events, which are driven by environmental forces. 
In a technical sense Turbulence was calculated as $\sum \mathrm{X}_{\mathrm{i}}$ where $\mathrm{X}_{\mathrm{i}}$ is the occurrence of a change $i$. Emphasising the pivotal nature of key changes, we observe that they occur, on average, just eight times over the lifetime of the long-lived small firm (see Table 1). The range of key changes was fourteen and the maximum number of changes was just sixteen. Thus owner managers were clearly being very discriminating in interpreting any change in their operations as being a key change.

Measures of agility and speed were obtained as follows. For the key changes identified by each long-lived small firm, the owner-manager was asked to select those three which were most important to the running of their business, since inception. Just three changes were extracted for more detailed consideration, because pilot work had suggested that this was the best way of capturing salient information from the interviewing. A simple diagrammatic device (see Figure 1) was used in interviews with owner managers to explain our focus of interest. We explained that we wanted to know what had precipitated organisational change, and what adjustments had been made after it had been achieved. We used the term 'precipitating influences' to describe the forces, which led to organisational change. In a similar vein, we used the term 'consequential adjustments' to describe those adaptations which followed on from organisational change.

An advantage of the Figure that we used was that it made quite explicit the pattern of causal relationships. This, in turn, made it easier to get owner managers to estimate the intervals of time that occurred between precipitating influences and organisational change, and between organisational change and consequential adjustments.

\section{Figure 1}

\section{Explanation of Causation}

Before

Precipitating Influences
Organisational

Change
After

Consequential Adjustments 
Owner managers were presented with a show-card on which they could identify precipitating causes and consequential adjustments. This show-card contained a comprehensive list of 30 potential categories of precipitating causes and consequential adjustments. An extract from this show card is given in Figure 2. ${ }^{6}$ That Figure also indicates how responses were recorded. Figure 2 indicates some of the factors we were interested. Other ones included credit policy, finance, trade intelligence and cash-flow. These factors were liberally. For example, if a respondent checked demand as a precipitating or an adjustment factor, it could be as a result of either an increase or a decrease in demand. The important thing was that a change had occurred in this factor, which drove or followed the organisational change.

This line of inquiry was conducted for three organisational changes, over the mature firm's lifetime, that the owner manager had identified. Thus the sequence by which the data were elicited were as follows. First, the owner manager was asked to identify the precipitating influences from the list of 30 factors (in the format displayed, in an abbreviated way,) in Figure 2. Second, the owner manager was asked to identify the number of months ( $\mathrm{pt}$, which stands for 'PrecipitatorTime') which elapsed between identifying the precipitating cause and the identifying the organisational change within the firm. Third, owner managers were asked to identify the consequential adjustments which followed the change in organisational form. Fourth the owner managers were asked to identify the number of months (at, which stands for 'AdjustTime') which had elapsed between the occurring of the organisational change and the appearance of the consequential adjustment.

\section{Figure 2}

\section{Response Format for Calibrating Change}

\begin{tabular}{|c|c|l|c|c|}
\hline Time & Before & Factors & After & Time \\
\hline & $\square$ & 1. Headcount & $\square$ & \\
\hline & $\square$ & 2. Demand & $\square$ & \\
\hline & $\square$ & 3. New niches & $\square$ & \\
\hline & $\square$ & 4. Tax efficiency & $\square$ & \\
\hline
\end{tabular}

Agility, is the ratio number of precipitating causes $(\mathrm{P})$ to number of consequential adjustments (A). Agility was calculated for each of the three main changes identified by 
each respondent by counting the number of precipitating factors and adjustment factors for each change. A larger ratio implies that the firm is more agile and thus more flexible. Formally agility is measured by the count of precipitating factors $(\mathrm{P})$ divided by the count of adjustments (A) averaged over three main changes. Thus agility is calculated as

$$
\frac{\sum_{c=1}^{m}\left(P_{c} / A_{c}\right)}{\sum_{c=1}^{3} m_{c}}
$$

where $A=\sum a_{j m}$ where $a_{j m}$ is the occurrence of adjustment $j$ for each change $m$ and $P=$ $\sum \mathrm{p}_{\mathrm{jm}}$ where $\mathrm{p}_{\mathrm{jm}}$ is the occurrence of precipitating factor $\mathrm{j}$ for each change $\mathrm{m}$ where $\sum_{\mathrm{c}=1}^{3} \mathrm{~m}_{\mathrm{c}}$. On average the firm's agility ratio is 0.8737 . This ratio is less than 1 , which implies that long-lived small firms find it difficult to limit the amount of trimming (the number of adjustments) they make as a consequence of organisational change. The average number of Precipitator or precipitating causes is (Precipitator) is 5.27, whereas the average number of consequential adjustments (Adjust) is $7.31 .^{7}$

The second measure the overall speed of adjustment is another important aspect of flexibility. Three measures of speed of adjustment can be obtained from the questionnaire structure, for each of the three main organisational changes identified by the owner manager. These are: the length of time from the emergence of precipitating factors to the organisational change; the length of time from the organisational change to changes in adjustment factors; and the summation of the two. The shorter are these time periods, the more flexible is the long-lived small firm. The overall speed of adjustment can be obtained by summing the average precipitating time and the average adjustment time. It is calculated here as

$$
\frac{\sum_{\mathrm{c}=1}^{3}\left(\mathrm{P}_{\mathrm{t}}+\mathrm{A}_{\mathrm{t}}\right)_{\mathrm{c}}}{\sum_{\mathrm{c}=1}^{3} \mathrm{~m}_{\mathrm{c}}}
$$


The average precipitating time is the sum of the number of months between detecting each precipitating factor (or 'driver') and making the organisational change, divided by the number of precipitating factors. Average precipitating time $\mathrm{P}_{\mathrm{t}}$ is calculated as $\sum \mathrm{pt}_{\mathrm{jm}} / \sum \mathrm{p}_{\mathrm{jm}}$ where $\mathrm{pt}_{\mathrm{jm}}$ is the length of time between each precipitating factor $\mathrm{j}$ and the occurrence of each main organisational change $\mathrm{m}$. The average adjustment time is the sum of the number of months between making the organisational change and each consequential adjustment, divided by the number of adjustment factors. Average adjustment time $\mathrm{A}_{\mathrm{t}}$ is calculated by $\sum \mathrm{at}_{\mathrm{jm}} / \sum \mathrm{a}_{\mathrm{jm}}$ where $\mathrm{at}_{\mathrm{jm}}$ is the length of time between the occurrence of each main change $m$ and each adjustment $j$. On average the firm's overall adjustment speed is 22 months. The less the time taken in adjustment, the more flexible is the small firm. The average total precipitating time (PrecipitatorTime) was 76 months whereas the average total adjustment time (AdjustTime) was 54 months. ${ }^{8}$ As the average number of precipitating factors was less than the number of adjustments this suggests that small firms lingered until they were certain that change was required and then responded quickly.

A quantitative indicator of performance was obtained from a multidimensional scale with 28 items. These covered the strategic ( 9 items), financial (4 items), and organisational aspects (4 items) of the long-lived small, as well as environmental forces (11 items) affecting their performance. ${ }^{9}$ We would hold that our approach has advantages over the using of conventional financial data. These are subject to accounting conventions (e.g. the reporting protocol) that make them difficult to interpret in sensible economic terms. This is especially true of accounting profit, as opposed to economic profit. Thus rate of return, or profitability, may both seem suitable quantitative indicators for assessing the performance of the mature small firm, but this fails to grapple with quite simple aspects of reality, like the fact that profit itself may be ill-defined in most small firms e.g. profit may not be well distinguished from income. We could, of course, have substituted a simple single question on self-appraisal of performance, for the more conventional type of question on rate of return. However, we would argue that our multidimensional approach has two main advantages over the single question approach. First, it produces detailed measurement across a wide spectrum performance-relevant variables, rather than a single variable. Second, by diluting 
variable specific effects, it produces a more comprehensive (and stable) of what is meant by performance, allowing common influences to come through (DeVellis, 1991).

The question put to owner managers was as follows: "We'd like to know what has kept you in business down the years. Some things are good for business and some things are bad. What effect have the following had? ". The owner managers were asked to rate $^{10}$ each item on a scale of 0 to 100 where 100 is good, and 0 is bad and 50 is neutral. They did so by placing a cross on the line, in this way calibrating the influence they judged this item to have had, based on actual experience of running the business. If an item was not applicable they were asked to say so. An extract of the scale is reproduced in Figure 3. We found that owner managers of our long-lived small firms could readily draw on their experience of running a business, to self-appraise the influence that each of these items had had on their performance. A self-assessment of each item's influence on the performance of the firm was thus obtained. Thereby a measure of overall performance, which summed these individual scores, was computed. An overall score for performance (Perform) was calculated for each firm, based on the summation of ratings for factors, normalised to take account of those items that were not applicable. Out of a maximum performance score of 100, the average long-lived small firms scored 67. In other words, for these long-lived small firms, many potential influences had a positive effect on performance.

\section{Figure 3: Response Format for Performance Indicator}

4.1 We'd like to know what has kept you in business down the years. Some things are good for business and some things are bad. What effect have the following had?

\section{[Show with a cross whether the effect was good or bad.]}

Technology

Rival's Innovation

N/A Bad

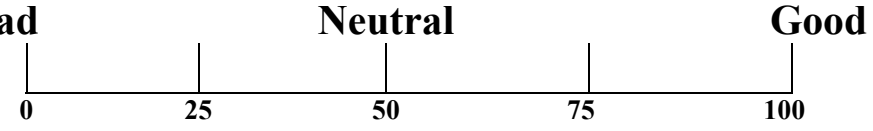

Bad
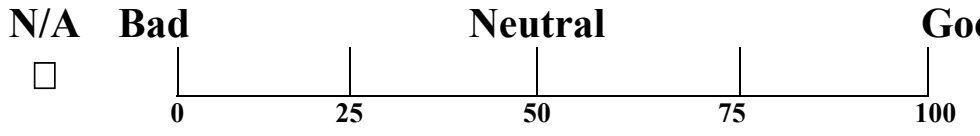

Regulation
Neutral

Good
N/A Bad

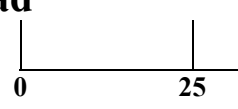


Table 2 examines our measures of turbulence, flexibility and performance, depending on firm type. We note that firm type is closely correlated with firm size. We have tested for differences between the mean values of these variables, across the sole proprietor, partnership and private company firm types, within our sample. We find that there is a significant difference in the mean sizes, whether measured by employment or sales. However, there are no significant differences in the means of our measures of turbulence, agility or speed, across firm types. This lends general support to Carlsson's (1989) theory that there are some aspects of flexibility, which are not related to size. There also find that there is no difference in the subjective measure of performance for different firm types (and therefore sizes). This is also true if we use a more 'objective' conventional measure of performance, like labour productivity (LabProd), here defined by sales divided by fulltime equivalent employees. The central concern of our paper is whether our dimensions of flexibility and turbulence are helpful in explaining long run differences in the performance of small firms, given that there are no significant differences in the performance and flexibility of these small firms by virtue of their type and size. 
Table 2: Flexibility, Firm Size and Performance**

\begin{tabular}{lrrr}
\hline Variable & $\begin{array}{c}\text { Sole Proprietor } \\
(n=16)\end{array}$ & $\begin{array}{c}\text { Partnership } \\
(n=19)\end{array}$ & $\begin{array}{r}\text { Private Company } \\
(n=28)\end{array}$ \\
\hline Sales* & 219812 & 557526 & 1372821 \\
& $(143026)$ & $(455994)$ & $(1855391)$ \\
Employees (FTEs)* & 5.94 & 7.24 & 22.18 \\
& $(5.85)$ & $(4.15)$ & $(27.18)$ \\
Turbulence & 7.94 & 7.11 & 8.43 \\
& $(3.07)$ & $(3.31)$ & $(4.46)$ \\
Agility & .8896 & .8781 & .8617 \\
& $(.3431)$ & $(.5316)$ & $(.3554)$ \\
Speed & 19.5478 & 20.6476 & 23.9555 \\
& $(13.1333)$ & $(15.9629)$ & $(18.0923)$ \\
Perform & 69.1519 & 66.5217 & 66.8754 \\
& $(9.4962)$ & $(8.2249)$ & $(7.2764)$ \\
LabProd & 55032 & 72339 & 64425 \\
& $(45063)$ & $(3134)$ & $(76271)$ \\
\hline
\end{tabular}

*Significant difference in means using ANOVA at $\alpha=.05$ and $\mathrm{F}_{(260)}$

**The standard errors are in parentheses.

\section{Estimates}

To examine the degree to which our different measures of flexibility and firm specific turbulence affected the performance of our long-lived small firms, we used Heckman's selection model (Lee 1982 and 1983; Heckman 1976; Davidson \& MacKinnon 1993). This model assumes that there exists an underlying relationship between our performance variable (Perform) and our measure of firm specific turbulence (Turbulence), along with our measures of flexibility (e.g. Adjust, AdjustTime) for our sample of long-lived small firms ${ }^{11}$. This may be expressed:

Perform $=\beta_{0}+\beta_{1}$ Turbulence $+\beta_{2}$ Precipitating $+\beta_{3}$ Adjust $+\beta_{4}$ PrecipitatorTime $+\beta_{5}$ AdjustTime

$$
+\mathrm{u}_{1 \mathrm{i}}
$$

where $\mathrm{u}_{1} \sim \mathrm{N}(0, \sigma)$. We may expect sample selection bias to exist, as the measures of performance, turbulence and flexibility are only observed for long-lived small firms, and not for all firms, including non-survivors. The first step of this procedure is to estimate a binary probit model of the survival of long-lived small firms. This may be written:

$$
\mathrm{S}=X \beta+u_{2 I}
$$


where $\mathrm{S}$ is a binary variable, which is set equal to unity if the firm has survived, but otherwise to zero. The matrix $X$ contains observations on those factors thought to influence the long-run survival of small firms (e.g. number of full time and part-time employees, gearing and number of product groups), the vector $\beta$ contains the estimated parameter coefficients and $\mathrm{u}_{2} \sim \mathrm{N}(0,1)$. The correlation between $\mathrm{u}_{1}$ and $\mathrm{u}_{2}$ is given by $\rho$. From the binary probit estimation we can calculate the so-called inverse Mills ratio (lambda). This inverse Mills ratio is used as an additional regressor in the general least squares estimation of our performance equation (3) above. Heckman's (1979) two-step procedure provides consistent estimators, under certain regularity conditions.

Initially our model was run on a sample of 186 firms, which included sub-samples from each of the three parent samples (see Table 4). This includes the 63 surviving longlived small firms for which we have complete data to estimate the performance relationship (3), as well as the 123 non-surviving firms for which we have parsimonious data, but enough to estimate the selection relationship (4). For Heckman two-step estimation for this sample of 186 firms, the selection equation (4) (containing largely size measures) was estimated using common data across these three sub-samples: industrial sector (Sector); start year (StYear); sales in early years of trading (StSales); full-time employees (Ftemployees); and part-time employees (PtEmployees). Overall, this estimation represents our attempt to use the available data in the most comprehensive fashion.

For comparative purposes, Table 3 presents generalised least squares estimators for the performance relationship (3) without sample selection. In Table 3 we report on generalised least squares estimators for the performance equation (3) without sample selection. Here our goal is to estimate, in a preliminary way, the impact of our flexibility and turbulence measures on performance. An initial inspection of the graph of the residuals from an exploratory ordinary least squares regression, plotted against the predicted values, suggested that the residuals were increasing with values of the predictors. To correct for this, the ordinary least squares model was weighted by the reciprocal of Sales, as Sales were found to be proportional to the absolute value of the residuals, using the Glejser test for heteroskedasticity, Davidson and McKinnon (1993, ch.11). This procedure was found to remove the heteroskedasticity. The generalised least 
squares model presented in Table 3 had an $\mathrm{R}^{2}$ of 0.99 with probability value of 0.000 . Although this is highly significant, we focus discussion on the results of Tables 4 and 5, because these estimates have been corrected for selectivity bias. We do so on a precautionary basis, although it will be observed that the results in Tables 4 and 5, which use sample selection methods are broadly similar to those in Table 3 . We find that $\rho$, the correlation between the disturbances in the performance and selection equations is close to zero, suggesting selectivity bias is not a major problem. Therefore what is true of our analysis in Tables 4 and 5 would be true also of an analysis in Table 3.

\subsection{Selection Equations}

We start first with the sample selection equations, though we note the main burden of interpretation in this article attaches to the performance equations. Our discussion turns first, therefore, to the selection equation of Table 4. This is computed with the largest sample size possible $(n=186)$, using data from all three of the parent samples. We observe that sales at first interview (StSales) is significant. That is, size early in the lifecycle has a positive effect on long run survival. This is a kind of effect one would expect to observe, in terms of fundamental modelling of the small firm's growth process. For example, if the time series of sales from inception is a random walk, terminating when the process hits the absorbing barrier of zero sales, the mean passage time to exit is higher, the greater are first period sales. The effect of size has quite a high positive elasticity (using elasticities computed at the means): a 1\% increase in mean sales at start-up increases the probability of survival by $0.2 \%$.

Turning now to the sample selection equation in Table 5 , it is to be noted that the sample size is now smaller $(\mathrm{n}=89)$ and additional variables are included, on the gearing ratio (Gearing) and the number of product groups (ProdGroup). Here, we have gained additional variables for the selection equation but at the cost of having access to only two of the three parent samples. We note that the number of product groups (ProdGroup) is significant at the $10 \%$ level in Table 5 . This variable also has a very high elasticity (0.52). The importance of product group size has been emphasised in other works, including Reid (1993, ch.9). The work of Ungern-Sternberg (1990) provides and explanation of this effect in terms of diversification of the product portfolio, as an 
accommodation to fluctuating demand for individual products. In general, the selection equations of Tables 4 and 5 should be regarded as being statistical devices for guarding against sample selection bias, in the context of a Heckman two-step adjustment procedure, rather than as sophisticated models of small firm survival. Our main focus is, of course, on the performance equation.

\subsection{Performance Equations}

Performance is examined using three estimators. First, generalised least squares estimators, without sample selection, using a sample size of $n=63$ (see Table 3). Second, Heckman sample selection estimation, using a sample size of $n=186$ (see Table 4). Here, the selection equation uses all available sample data, but is restricted in the number of variables that can be used. Third, Heckman sample selection estimation, using a sample size of $n=89$ (see Table 5). In this case, a smaller sample size is used (accessing just two out of the three parent samples), but a wider range of variables (e.g. including gearing). The focus in the discussion to follow will be on the estimates with sample selection of Tables 4 and 5 .

By reference first to Table 4, we find that firm specific turbulence (Turbulence) has a negative impact on our count measure of qualitative performance (Perform). Judged by elasticities at the means, this variable has a larger impact than any other does on performance. Indeed, a 1\% increase in the mean count of organisational changes reduces performance by as much as $0.24 \%$. A similar effect is found in Table 5, with an even higher elasticity. Excessive organisational change seems to be to the detriment of the long-lived small firm's performance. As a business journalist commented on an earlier draft of our paper " many a meddle makes a muddle of the business" Jamieson (2002). There is an intuitive explanation for this, which supports the interpretation of Reid and Smith (2000b). It is that the relationship between firm specific turbulence and firm performance tends to be U shaped. Both poorly performing firms (or "stagnant" firms in their terminology) and highly performing firms (or "adaptive" firms in their terminology) tend to be relatively active in undertaking changes, compared to moderately performing firms. Thus, stagnant firms are relatively active in making organisational changes, just to survive, whereas adaptive firms are very active in making organisational changes, to 
improve performance and promote growth. It may be that the presence of a number of these relatively "stagnant" firms in our sample, doing really badly (sometimes called the "living dead") is driving the negative relationship between Turbulence and Performance. If so this suggests that there is another selection process here, beside the long-run test of economic survival. It may take the form of deciding whether or not the small firm grows to be a large firm - a "gazelle" as described by Birch (1996). Part of the reason for the existence of gazelles may be that they are intrinsically designed to be of a relatively large scale, and that they very rapidly grow towards this target size after inception. Many of the small firms in the sample have succeeded in the first selection process but very few are triumphant in the second. ${ }^{12}$

A complex relationship exists between flexibility (as measured by our Precipitator, Adjustments, Precipitator and PrecipitatorTime) and performance according to the evidence presented in both Tables 4 and 5. We observe first that the number of factors which the owner manager can identify as precipitating organisational change (Precipitator) has a highly significant and positive effect upon performance, and this effect is large judged by the elasticity at the mean. Being aware of factors impinging on the small firm, by effective scanning of the business environment (e.g. Wickam, 2001 p.324) is an aspect of entrepreneurial alertness which should be reflected in the count variable Precipitator. We believe that it is this capacity to identify precipitating factors that are potential drivers of performance enhancing change which is important. That is, the owner manager for whom the count variable Precipitator is high, is not just passively noting changes in the environment. Rather, he is actively seeking signs of environmental change, to which the business could be better adapted. In term of options reasoning, the greater the array of factors embraced in the variable Precipitator the higher the potential option value generated (see McGrath, 1999, proposition 1). Furthermore, the PrecipitatorTime variable in Table 4 has a highly significant negative coefficient and a moderately large elasticity. This suggests that the more rapidly the mature small firm takes action, typically in the shape of organisational change, in the face of critical changes in its environment, the better is its performance.

To pin down matters in more quantitative terms, if one looks at Table 4, a $1 \%$ increase in the Precipitator variable increases performance by $0.15 \%$; and a $1 \%$ increase 
in the mean precipitating time (PrecipitatorTime) reduces performance by $0.07 \%$. Again, thinking in real option terms, this evidence is saying that, given a larger number of detected drivers of a change, a firm has greater certainty that change is necessary to improve performance, including sheer survival. However, if a firm is slow to respond to detected drivers of change, it risks being too late to achieve improvements in performance from instigating the organisational change. That is, it may be that a trade-off exists. The longer is the PrecipitatorTime, the more the Precipitators that are detected. The more Precipitators, the greater the certainty surrounding the performance implications of the change. But the longer the PrecipitatorTime the greater the risk that the mature small firm will fail to capture some of the benefits of improved performance. Comparing the Precipitator and PrecipitatorTime variables of Table 4 with Table 5 one finds a set of results that is captured by the discussion above. The significance level goes up, as do the magnitudes of both the elasticities, in the case of Table $5(\mathrm{n}=89)$, therefore the analysis above applies all the more so.

As a consequence of organisational change, the mature small firm is subject to a number of adjustments, examples of these might include headcount, stock levels or credit policy. There are some differences between Tables 4 and 5 in the behaviour of the variable Adjust which measures these effects. Specifically, the coefficient of Adjust is not significant in Table 4 (sample size $\mathrm{n}=186$ ), but has a positive and significant effect on performance (see Perform) when we turn to the evidence in Table 5 (where $\mathrm{n}=89$ ) and a higher elasticity. In the latter case, a $1 \%$ increase in the mean count of adjustments (Adjust) increases performance by $0.10 \%$. Turning now to AdjustTime, this has a positive and significant impact on performance in both Tables but a relatively small elasticity.

What we learn from this is that a higher number of adjustments (Adjust), other things being equal, following organisational change, increases the performance of the long-lived small firm. A higher absolute number of adjustments also signals greater commitment by the firm to organisational change. Furthermore, a greater commitment by these firms indicates that the organisational change has significant implications for firm performance (including survival), Ghemawat (1991).

In Table 5, the number of consequential adjustments (Adjust) has a smaller impact on Performance than does the number of precipitating causes (Precipitator) $(0.1 \%$ versus 
$0.2 \%$ respectively). Adopting a real options line of reasoning, this suggests that the certainty of the economic implications of an organisational change within the mature firm is more important than the number of adjustments made following the change. Faulty evaluations of the potential benefits of strategic change can impact negatively on small firm performance, McGrath, 1999.

The variable AdjustTime refers to the lag between organisational change (instigated by some precipitating factors) and consequential adjustments e.g. of headcount, of stock level etc. A detailed definition is given in the Appendix. The statistical import of the variable AdjustTime is similar across Tables 3, 4 and 5. The coefficient of AdjustTime is positive and highly statistically significant and has a moderate elasticity. A $1 \%$ increase in the mean adjustment time increases performance by $0.09 \%$. Although a mature small firm which is slow to adjust, may be having difficulty in altering its factors of production (e.g. headcount), and in this sense lacks agility, the interpretation we prefer runs in terms of a real options analysis (Bowman and Hurry, 1993; Luehrman, 1998; and McGrath, 1999). We would hold that the statistical behaviour of the AdjustTime variable seems to suggest the following argument. Extending AdjustTime can attenuate potential downsides by limiting fixed costs and irreversible investments. This should raise the bundled value of the portfolio of adjustments, typically investments, that might be labelled the mature small firm's "strategy" in the light of organisational change, Luehrman, (1998), McGrath, (1999). By staging adjustments, a firm increases its option value to withdraw from change, or to continue to invest, having resolved uncertainties, thereby increasing its flexibility. However, the staging of adjustments may imply that it takes longer to receive payoffs from the organisational change. Thus increases in the option value deriving from flexibility may come at a cost.

We can illustrate this argument by reference to a brief case study of a firm within our sample, see Judge (2002). The firm in question was a corporate design and communications company. The firm's activities had a high creative content, and involved producing images and various forms of documentary reporting relating to its clients' business. The industry as a whole was subject to the impact of a major precipitating factor, namely the emergence of digital technology. The organisational 
change that was undertaken involved researching the market and determining the consequential needs of suppliers and trading partners. The entrepreneur who ran the firm was acutely aware of the potential for failure to successfully adopt the new technology. He invested in a pilot project for digital software, and then on the back of its success a further investment was made in a new team of people "to deal specifically with that side of the business". The entrepreneur in question said "We forged close links with other companies such as programming firms and internet service providers, so we could be sure that, if we went cold on the digital technology, those of our clients that were interested could still be serviced by someone else."

Overall, reflecting on the full set of results displayed in Tables 3, 4 and 5, we find them to be broadly similar. A possible exception to this is the variable Adjust, whose coefficient is only significant in Table 5 . On the other hand, Table 5 is arguably the most satisfactory set of estimates in terms of overall significance, individual coefficient significance, magnitudes of elasticities, and specification of the selection equation. Regarding the latter, we sacrificed sample size in order to put market (ProdGroup) and financial variables (Gearing) into the selection equation. This seems to have paid off, statistically speaking, in that we can say more, with a smaller sample size. For this reason Table 5 contains our preferred specification.

If parsimony were our only goal, the results of Table 3, on the smallest sample size ( $\mathrm{n}=63$ ) would be recommended. However, they lack significant for the coefficient on Adjust, and leave one uneasy about possible consequences of sample selection bias being neglected. In fact, when one looks at the diagnostics relating to the Heckman twostep adjustment procedure in Tables 4 and 5, the Mills Lambda is not statistically significant in either case and the correlation between disturbances on the performance and selection equations is low. We never the less prefer the results of Table 5 because we feel there is no harm in being careful on the sample selection issue, and because, at the margin any adjustment for bias of this sort might have a marginal impact upon the performance equation (which seems to have been the case with the Adjust variable).

We aim to undertake further research which will build on these estimates, using to interaction effects. One such interaction is that between the count of precipitating factors (Precipitator) for organisational change (e.g. industry-wide innovation), and the time it 
takes the firm to respond to them (PrecipitatorTime) by implementing an organisational change (e.g. re-skilling of staff). The other, is the interaction between the number of adjustments (Adjust) which the firm undertakes (e.g. an increase in head-count) as a consequence of organisational change, and the time it takes for consequential adjustments to be implemented (AdjustTime).

Table 3 Generalised Least Squares $(n=63)$

\begin{tabular}{lrrrr}
\hline Estimation & Coeff. & Std. Error & Prob. & \multicolumn{1}{c}{$\begin{array}{c}\text { Elasticities } \\
\text { at mean }\end{array}$} \\
\hline$G L S$ & & & & \\
Turbulence & -1.701831 & 0.2878478 & 0.000 & -0.2525534 \\
Precipitator & 1.852652 & 0.5263581 & 0.001 & 0.151157 \\
Adjust & 0.2762535 & 0.4601972 & 0.551 & 0.0306325 \\
PrecipitatorTime & -0.0819913 & 0.0435265 & 0.065 & -0.0648971 \\
AdjustTime & 0.1163448 & 0.0189599 & 0.000 & 0.0940773 \\
Constant & 67.7238 & 3.10898 & 0.000 & 1.041584 \\
\hline
\end{tabular}

Note: $\mathrm{R}^{2}$ adjusted $=0.99 ; \mathrm{F}_{(6,57)}=67.6$ Prob. $>\mathrm{F}=0.0000$ 
Table 4 Heckman Sample Selection Model $(n=186)$

\begin{tabular}{|c|c|c|c|c|}
\hline Estimation & Coeff. & Std. error & Prob. & $\begin{array}{c}\text { Elasticities } \\
\text { at mean }\end{array}$ \\
\hline \multicolumn{5}{|l|}{$G L S$} \\
\hline Turbulence & -1.679331 & 0.1928492 & 0.000 & -0.2470291 \\
\hline Precipitator & 1.886974 & 0.3946002 & 0.000 & 0.1526074 \\
\hline Adjust & 0.2794347 & 0.3605423 & 0.438 & 0.0307136 \\
\hline PrecipitatorTime & -0.0883651 & 0.0254937 & 0.001 & -0.0693288 \\
\hline AdjustTime & 0.1156801 & 0.0114233 & 0.000 & 0.0927197 \\
\hline Constant & 67.18461 & 1.975877 & 0.000 & 1.02423 \\
\hline \multicolumn{5}{|c|}{ Selection Equation } \\
\hline Sector & -0.0416648 & 0.2002715 & 0.835 & -0.0727281 \\
\hline FTEmployee & -0.0040999 & 0.0120681 & 0.734 & -0.0260707 \\
\hline PTEmployee & -0.013339 & 0.0171223 & 0.436 & -0.0422587 \\
\hline StYear & -0.0030649 & 0.0111117 & 0.783 & -0.2644557 \\
\hline StSales & $5.00 \mathrm{E}-07$ & $2.50 \mathrm{E}-07$ & 0.045 & 0.1986496 \\
\hline Constant & -0.2515869 & 1.007342 & 0.803 & \\
\hline Mills-lambda & 814015 & 1065096 & 0.445 & \\
\hline Rho & 0.12243 & & & \\
\hline Sigma & 6649056 & & & \\
\hline Wald chi2(6) & 10035.63 & & & \\
\hline Prob $>$ chi2 & 0.0000 & & & \\
\hline
\end{tabular}


Table 5 Heckman Sample Selection Model $(n=89)$

\begin{tabular}{|c|c|c|c|c|}
\hline Estimation & Coeff. & Std. error & Prob. & $\begin{array}{c}\text { Elasticities } \\
\text { at mean }\end{array}$ \\
\hline \multicolumn{5}{|l|}{$G L S$} \\
\hline Turbulence & -1.793477 & 0.215148 & 0.000 & -0.2727101 \\
\hline Precipitator & 2.405389 & 0.5098721 & 0.000 & 0.2010891 \\
\hline Adjust & 0.945891 & 0.4272299 & 0.027 & 0.1074695 \\
\hline PrecipitatorTime & -0.1539495 & 0.0378933 & 0.000 & -0.1248546 \\
\hline AdjustTime & 0.1029675 & 0.0132173 & 0.000 & 0.08531140 \\
\hline Constant & 63.40325 & 2.460651 & 0.000 & 0.9991559 \\
\hline \multicolumn{5}{|l|}{ Selection Equation } \\
\hline Sector & 0.2813531 & 0.319048 & 0.378 & 0.4416197 \\
\hline FTEmployee & -0.0038659 & 0.0208656 & 0.853 & -0.0221049 \\
\hline PTEmployee & -0.0122082 & 0.01904 & 0.521 & -0.0347784 \\
\hline StYear & -0.0160978 & 0.0272271 & 0.554 & -1.249021 \\
\hline StSales & $7.55 \mathrm{E}-07$ & $4.43 \mathrm{E}-07$ & 0.088 & 0.2697655 \\
\hline Gearing & -0.0002321 & 0.0005276 & 0.660 & -0.0272064 \\
\hline ProdGroup & 0.211399 & 0.1235461 & 0.087 & 0.5181847 \\
\hline Constant & -0.1704371 & 2.369223 & 0.943 & \\
\hline Mills - lambda & 284672.3 & 1754376 & 0.887 & \\
\hline Rho & 0.03646 & & & \\
\hline Sigma & 6820567 & & & \\
\hline Wald chi2(6) & 7483 & & & \\
\hline Prob $>$ chi 2 & 0.0000 & & & \\
\hline
\end{tabular}




\section{Conclusion}

This paper examines the effects of firm-specific turbulence and various dimensions of flexibility on the performance of the long-lived small firm in Scotland. In our work, we identify the main factors that influence the performance of long-lived small businesses positively. First, they must be alert. They must good at recognising drivers of change. Second, they must be speedy. They should be quick to adapt their organisation in the light of these forces of change. Third, once organisational change has been implemented, the entrepreneur should follow through on all necessary adjustments. However, this should not be done impulsively. Such adjustments typically involve investments which are in the nature of exercising an option. Fourth, delay on adjustment may have beneficial consequences for performance if it reduces uncertainty and diminishes irreversibility. Acting in these ways, entrepreneurs can have a positive influence on performance. On the other hand, as we explore below, firm specific turbulence has a negative effect on performance.

Performance is regarded as a multidimensional variable. In our case it is constructed from interview evidence with entrepreneurs covering competitive environment, financial management, organisational structure and business strategy. This and all other evidence were collected by fieldwork methods. The performance, firm specific turbulence and flexibility measures are all novel. A variety of performance models were estimated using generalised least squares estimation (with heteroskedastic adjustment) with or without sample selection. When adjustment for sample selection bias was undertaken, two different specifications of selection equations were used, and the Heckman two-step procedure was adopted.

Whilst flexibility, playing the various roles illustrated above, had a positive effect upon performance, this was not true of our firm-specific measure of turbulence (Turbulence). This is a count variable of the frequency of organisational change. It had a highly significant and strong negative effect on performance. This firm-specific turbulence refers to the total amount of 'trimming' of its activities that the firm undertakes. We find that too much 'trimming' reduces performance. For example, it 
wastes resources, and suggests false or imprudent moves, which then require correction. The smart approach is to stage the commitment of resources to a new strategy. This allows you to pull back if things do not pan out as you expected. Technically, it increases the "option value" of the small firm. 


\section{Appendix}

Definition of variables used in main text

\begin{tabular}{|c|c|}
\hline Age & Age of firm, in years. \\
\hline Agility & $\begin{array}{l}\text { Agility is the ratio of precipitating to adjustment factors averaged } \\
\text { over three main changes. }\end{array}$ \\
\hline Adjust & $\begin{array}{l}\text { Count of adjustments averaged over three main changes }= \\
\sum a_{j m} / 3 \text { where } a_{j m} \text { is the occurrence of adjustment } j \text { for each main } \\
\text { change } m\end{array}$ \\
\hline AdjustTime & $\begin{array}{l}\text { Total adjustment time averaged over three main changes }=\sum \mathrm{at}_{\mathrm{jm}} / 3 \\
\text { where } \mathrm{at}_{\mathrm{jm}} \text { is the length of time between the occurrence of each } \\
\text { main change } \mathrm{m} \text { and each adjustment } \mathrm{j}\end{array}$ \\
\hline Employees & Number of full-time equivalent employees in 2001 \\
\hline FtEmployee & Number of full-time employees at start-up \\
\hline Gearing & $=$ bank loan/personal injection \\
\hline LabProd & $=$ Sales/ Employees \\
\hline Perform & $\begin{array}{l}=\sum \mathrm{f}_{\mathrm{i}} / \mathrm{n} \text { where } \mathrm{f}_{\mathrm{i}} \text { is the self appraised score between } 0-100 \text { for each } \\
\text { factor averaged overall factors } 1 \text { to } \mathrm{n} \text { which were applicable. }\end{array}$ \\
\hline Precipitator & $\begin{array}{l}\text { Count of precipitating factors averaged over three main changes }= \\
\sum \mathrm{p}_{\mathrm{jm}} / 3 \text { where } \mathrm{p}_{\mathrm{jm}} \text { is the occurrence of precipitating factor } \mathrm{j} \text { for each } \\
\text { main change } \mathrm{m}\end{array}$ \\
\hline PrecipitatorTime & $\begin{array}{l}\text { Total precipitating time averaged over three main changes } \\
=\sum \mathrm{pt}_{\mathrm{jm}} / 3 \text { where } \mathrm{pt}_{\mathrm{jm}} \text { is the length of time between each } \\
\text { precipitating factor } \mathrm{j} \text { and the occurrence of each main change } \mathrm{m}\end{array}$ \\
\hline ProdGroup & Number of product groups \\
\hline PtEmployee & Number of part-time employees at start-up \\
\hline Sales & Sales in 2001 \\
\hline Sector & $=0$ services $(\operatorname{sic} 61-99), 1=$ manufacturing $(\operatorname{sic} 01-60)$ \\
\hline Speed & $\begin{array}{l}\text { The overall speed of adjustment can be obtained by summing the } \\
\text { average precipitating time and the average adjustment time and } \\
\text { dividing by the number of main changes } \sum_{\mathrm{c}=1}^{3} \mathrm{~m}_{\mathrm{c}}\end{array}$ \\
\hline StSales & $\begin{array}{l}\text { Sales at first interview ( } 1985 \text { for SBE, } 1991 \text { for telephone, } 1994 \\
\text { for Leverhulme) at } 2001 \text { prices }\end{array}$ \\
\hline StYear & Year the business was established \\
\hline Survival & $=1$ survivor, 0 otherwise \\
\hline Turbulence & $\begin{array}{l}\text { Count of main changes over life of long-lived small firm }=\sum X_{i} \\
\text { where } X_{i} \text { is the occurrence of a change } i\end{array}$ \\
\hline
\end{tabular}




\section{Bibliography}

Acs, Z. and Audretsch, B. and Carlsson, B. (1990) Flexibility, Plant Size and Restructuring, in Acs Z. and Audretsch B. and Carlsson B. (eds) The Economics of Small Firms: A European Challenge, Dordrecht: Kluwer.

Carlsson, B. (1989) Flexibility and the Theory of the Firm, International Journal of Industrial Organisation, 7(2), 179-204.

Beesley, M.E. and R.T. Hamilton (1984), Small Firms Seedbed Role and The Concept of Turbulence, Journal of Industrial Economics, Vol.33(2).

Birch, D., (1996) Paper presented to the Jönköping International Business Conference on Enterpreneurship, SME's and the Macro Economy, 13-14 June 1996 (mimeo).

Bowman E. H. and Hurry D. Strategy Through The Options Lens: An Integrated view of Resource Investments and The Incremental-Choice Process, Academy of Management Review, Vol. 24, 760-782.

Brock, W. A. and Evans, S.E. (1989) Small Business Economics, Small Business Economics, 1(1), 7-20.

Davidson R. and MacKinnon J. G., (1993) Estimation and Inference in Econometrics, Oxford University Press; Oxford.

DeVellis, Robert. (1991) Scale Development: Theory and Applications. Vol. 26. Applied Social Research Methods Series. Sage Publications; London

Ghemawat, P. (1991) Commitment. The Free Press; New York.

Heckman, J. (1976) The Common Structure of Statistical Models of Truncation, Sample Selection and Limited Dependent Variables and a simple estimator for such models. The Annals of Economic and Social Measurement, 5, 475 - 492.

Jamieson, B. (2002), Many a Meddle May Make a Muddle of the Business, The Scotsman, $13^{\text {th }}$ June.

Jacobsen, L.R. (1986) Entrepreneurship and Competitive Strategy in the New Small Firm: An Empirical Investigation, University of Edinburgh, Department of Economics, $\mathrm{PhD}$ Thesis.

Judge, E. (2002) Golden Rule for Entrepreneurs Who Crave Success, The Times (Business Plus Section), Tuesday June 25, p32.

Kay, N. (1997), Pattern in Corporate Evolution. Oxford; Oxford University Press. 
Luehrman, T. A. (1998) Strategy as a Portfolio of Real Options, Harvard Business Review, Sept-Oct., p.89-99

Lee, L. F., (1982) Some Approaches to the Correction of Selectivity Bias, Review of Economic Studies, 49, 335-720.

Lee, L. F., (1983) Generalized Econometric Models with Selectivity Bias, Econometrica, 51(2), 507-512

Markusen, A. R and M.B. Teitz. (1985), The World of Small Business: Turbulence and Survival in Small firms in Regional Economic Development: Britain, Ireland and the United States edited by Storey D. J. Cambridge University Press.

Mata, J. (1993) Small firms in Portuguese Manufacturing Industries in Acs Z. and Audretsch B. Small Firms and Entrepreneurship: An East-West Perspective, Cambridge University Press, Great Britain.

McGrath, R. G. (1999) Falling Forward: Real Options Reasoning and Entrepreneurial Failure, Academy of Management Review, 24, 13-30

Mills, D. E. and L. Schumann (1985), Industry Structure with Fluctuating Demand, American Economic Review 75(4), 758-767

Piore, M. J. and Sabel, C. F. (1984), The Second Industrial Divide: Possibilities for Prosperity, Basic Books; New York.

Reid, G.C. (2002), Trajectories of Small Business Financial Structure, Small Business Economics, forthcoming.

Reid, G. C. and Smith J.A. (2000a), What Makes a New Business Start-up Successful?, Small Business Economics, 14(3): 165-182.

Reid, G. C. and Smith J.A. (2000b), The Impact of Contingencies on Management Accounting System Development, Management Accounting Research, 11, 427-450.

Reid, G. C. (1999), Complex Actions and Simple Outcomes: How New Entrepreneurs Stay in Business, Small Business Economics, 13, 303-315.

Reid, G. C. (1998) Limits to a Firm's Rate of Growth: The Richardsonian View and its Contemporary Empirical Significance, Ch.3 in B.J. Loasby and N.J. Foss (eds.) Capabilities and Coordination: essays in honour of G.B. Richardson; Routledge; London, 1998, 243-260.

Reid, G. C. (1996), Mature Micro-Firms and Their Experience of Funding Shortages, Small Business Economics, 8, 27-37. 
Reid, G. C. (1993) Small Business Enterprise: An Economic Analysis. London; Routledge.

Reid, G. C, Jacobsen L.R. and M. Andersen. (1993) Profiles in Small Business: A Competitive Strategy Approach. London; Routledge.

Reid, G. C. and M. E. Andersen (1992), A New Small Firms Database: Sample Design, Instrumentation and Summary Statistics, CRIEFF Discussion Paper, Dept. of Economics, University of St. Andrews, No. 9207

Reid, G. C. (1991), Staying in Business. International Journal of Industrial Organisation, 9, 545-56.

Reid, G. C. and Jacobsen, L.R. (1988). The Entrepreneurial Firm, Aberdeen; Aberdeen University Press.

Smallbone, D., North, D. and Leigh, R. (1992) Managing Change for Growth and Survival: The Study of Mature Manufacturing Firms in London During the 1980s. Working paper No.3 Planning Research Centre, Middlesex, Polytechnic.

Smith, J. A. (1999), The Behaviour and Performance of Young Micro Firms: Evidence from Businesses in Scotland. Small Business Economics ,13, 185-200.

Smith, J. A. (1999), Strategy Processes for Success. CRIEFF Discussion Paper, Dept. of Economics, University of St. Andrews, No. 9812

Smith, J. A. (1998), Strategies for Start-ups, Long Range Planning, 31(6), 857-872.

Smith, J. A. (1997), Small Business Strategy: An Empirical Analysis of the Experience of New Scottish Firms, PhD Thesis, University of Abertay, Dundee, Scotland.

Stigler, G. J. (1939), Production and Distribution in the Short Run, Journal of Political Economy, 47, 305-27.

Ungern-Sternberg, T. von (1990), The Flexibility to Switch Between Different Products, Economica, 57, 355-69.

Wickham, P. A. (1998) Strategic Entrepreneurship. Pearson Education; London.

\section{Endnotes}

This research has been undertaken with the generous support of Enterprise Ireland, to whom the authors make grateful acknowledgement. We should also like to thank many owner managers of small firms in Scotland. They gave generously of their time, over the period 2001-2, allowing us to collect high quality data in the field. The discussion paper version of this paper has benefited from previous presentations, in another form, of these 


\section{ideas to audiences in Cork and St Andrews. The authors remain responsible for any errors of omission or commission that this paper might yet contain.}

\footnotetext{
${ }^{1}$ Mills and Schumann (1985) developed a model where the existence of available technologies affords a tradeoff between static efficiency and flexibility so that in market environments with fluctuating demand it is possible for firms with higher minimum average cost also to survive if they are sufficiently flexible. Technologically diverse firms are able to compete with each other by relying on offsetting cost advantages as a result of this tradeoff. This technological diversity was associated with smaller sized firms because they use variable factors of production more rigorously than large firms.

${ }^{2}$ This was taken as the standard error of regressions adjusted for serial correlation where the natural logarithm of annual sales (or employment) from 1970 to 1980 was regressed onto a constant and a linear time trend. See Mills and Schumann (1985).

${ }^{3}$ Our sample is derived from three original samples. Data on the first parent sample of 86 small business enterprises (SBEs) in Scotland was collected between 1985 and 1988 using face-to-face interviews and examined in Jacobsen (1986), Reid and Jacobsen (1988), Reid and Jacobsen, Andersen (1993) and Reid (1993). This study examined factors effecting the survival, growth, performance and competitive strategy of these small firms in their early years. Of these 86 firms 25(29\%) survived. The 25 long-lived survivors from this sample are pooled with long-lived survivors from the other two parent samples of small business enterprises in Scotland. Data on the second sample was collected by telephone in 1991. These 160 firms were more mature at the time and examined in Reid (1996). The administered questionnaire covered financial aspects of a very small firms existence, including funding shortages, forms of external finance, relations with banks and perceptions of the venture capital market. 50 out of the 160 firms are still in business (a survival rate of 31\%). Thirdly 21 long lived small firms which were 10 years are more were also identified from a sample new business starts which were interviewed using face to face interviews between $1994-1997$ on their finance, costs, business strategy, human capital, organisation and technical change. These firms were examined by Reid and Smith (2000a) Reid (1991) and Smith (1997) and Smith (1998). 15 out of 21 were still trading (a survival rate of $71 \%$ ). According to figures produced by the Small Business Service (2001) in the Department of Industry and Trade between 1993 and 1996 the numbers registered for VAT had fallen by $40 \%$ which is a lot over a three year period (survival rate of $60 \%$ ) in comparison with a survival rate of approximately $30 \%$ over a 16 year period. This demonstrates how difficult it is to trying to generate a large sample of long-lived survivors with such high failure rates.

${ }^{4}$ See Reid (1993), Reid and Andersen (1992), Reid (1996) and Smith (1997).

${ }^{5}$ This created a duration variable from the point of inception for each change that had occurred.

${ }^{6}$ This question structure and design format improves on innovative aspects of the data design used in Reid and Smith (2000b) to explain changes in the management accounting system of small business enterprises using contingency theory. Cause and effect is identified here.

${ }^{7}$ The average number of Precipitators and the average number of adjustments are calculated by dividing
}

$\sum_{\mathrm{c}=1}^{3} \mathrm{P}_{\mathrm{c}} / \sum_{\mathrm{c}=1}^{3} \mathrm{~m}_{\mathrm{c}}$ and $\sum_{\mathrm{c}=1}^{3} \mathrm{~A}_{\mathrm{c}} / \sum_{\mathrm{c}=1}^{3} \mathrm{~m}_{\mathrm{c}}$ respectively.

${ }^{8}$ The average total precipitatingtime and the average total adjustment time are calculated by dividing

$\sum_{\mathrm{c}=1}^{3} \mathrm{~A}_{\mathrm{c}} / \sum_{\mathrm{c}=1}^{3} \mathrm{~m}_{\mathrm{c}}$ and $\sum_{\mathrm{c}=1}^{3} \mathrm{P}_{\mathrm{c}} / \sum_{\mathrm{c}=1}^{3} \mathrm{~m}_{\mathrm{c}}$ respectively.

${ }^{9}$ The factors were generated from theory and empirical evidence from studies examining differences in the performance of long-lived small firms.

${ }^{10}$ Rating factors along a continuum is a much easier task than ranking the list of factors from top to bottom especially for long lists of factors. The ranks can be tied when the factors are rated. The consistency which owner-managers rate factors on each scale item is also improved by defining the meaning respondents should assign to middle alternatives using adjectival labeling of points which is undertaken here. 
${ }^{11}$ The regressors are included in their raw count form. Multicollinearity would exist in the model if the measure of agility and speed were included as speed is a linear function of agility.

12 Another contributory factor is the standardisation of the measure of performance. If we do not standardise the measure of performance by dividing by the numbers of items on the multidimensional scale measuring performance applicable to each firm, a measure, which accounts for a the full 28 items underlying the performance of the firm can be calculated. This unstandardised measure of performance will account for greater variation in performance. As more items perhaps underlie the performance of adaptive firms and they should receive a higher score on this unstandardised measure of performance. As a greater number of items are perhaps applicable to adaptive firms the standardised measure of performance is biased downwards for adaptive firms. The standardised measure was calculated. Turbulence was positively correlated to this performance measure but as the residuals in the ordinary least squares regression were non normal the analysis of these models are not presented here. 